Research Paper

International Journal of Biological Sciences

ISSN 1449-2288 www.biolsci.org 2007; 3(6):349-355

CIvyspring International Publisher. All rights reserved

\title{
Superoxide Anion Radical Scavenging Activities of Herbs and Pastures in Northern Japan Determined Using Electron Spin Resonance Spectrometry
}

\author{
Mohammad Al-Mamun¹, Koji Yamaki², Toshiki Masumizu³, Yumi Nakai, Katsumi Saito5, Hiroaki Sanoㄹ, \\ Yoshifumi Tamura6
}

1. Faculty of Agriculture, Iwate University, Morioka, Japan

2. Post-Harvest Science and Technology Division, Japan International Research Center for Agricultural Science, Tsukuba, Japan

3. Faculty of Pharmaceutical Science, Sojo University, Kumamoto, Japan

4. Analytical Instrument Division, JEOL Ltd., Tokyo, Japan

5. Poultry Division, Experiment station for Animal Husbandry, Aomori Prefectural Agriculture and Forestry Research Center, Aomori, Japan

6. Forage Production and Utilization Research Team, National Agricultural Research Center for Tohoku Region, Morioka, Japan

Correspondence to: Dr. Yoshifumi Tamura, Forage Production and Utilization Research Team, National Agricultural Research Center for Tohoku Region, Akahira-4, Morioka 020-0123, Iwate, Japan. Phone: +81-19-643-3433; Fax: +81-19-641-7794; E-mail: fumi@affrc.go.jp

Received: 2007.07.04; Accepted: 2007.07.26; Published: 2007.07.30

Free radicals are not only destructive to the living cells but also reduce the quality of animal products through oxidation. As a result the superoxide anion radical $\left(\mathrm{O}_{2}{ }^{-}{ }^{-}\right)$, one of the most destructive reactive oxygen species, is a matter of concern for the animal scientists as well as feed manufacturers to ensure the quality of product to reach consumers demand. The superoxide anion radical scavenging activities (SOSA) of water and $\mathrm{MeOH}$ extracts of 2 herbs and 9 pasture samples collected from lowland and highland swards were determined against a 5,5-dimethyl-1-pyroline-N-oxide- $\mathrm{O}_{2}{ }^{\cdot-}$ spin adduct based on a hypoxanthine-xanthine oxidase reaction using electron spin resonance spectrometry. Both the water and $\mathrm{MeOH}$ extracted SOSA differed among the herbs and pastures. Species and altitudinal variations were observed between extraction methods. The herbs were higher in both water and $\mathrm{MeOH}$ extracted SOSA than the pastures except for water extracts of one pasture, white clover (Trifolium repens L.). Among the pastures, quackgrass (Agrophyron repens L.) showed higher SOSA in both the $\mathrm{MeOH}$ and water extracts, and timothy (Phleum pretense L.) showed higher $\mathrm{MeOH}$ extracted SOSA. It is apparent that the kind and amount of antioxidants differ among herbs and pastures. Animal health and quality of animal products could be improved by adequate selection and combining of herbs and pastures having higher SOSA.

Key words: Herbs and pastures, superoxide anion radical, scavenging activity, ESR, HPLC, altitudinal locations

\section{Introduction}

A part of the oxygen taken into living cells is changed to several harmful reactive oxygen species and free radicals. Once formed, free radicals can start a chain reaction leading to formation of more free radicals. Superoxide anion radical $\left(\mathrm{O}_{2}{ }^{-}\right)$is one of the strongest reactive oxygen species among the free radicals that are generated first after oxygen is taken into living cells. $\mathrm{O}_{2}{ }^{-}$changes to other harmful reactive oxygen species and free radicals such as hydrogen peroxide and hydroxyl radical. Although detailed relationships between antioxidants and animal health have not yet been reported, antioxidants supplied through diets improve the antioxidative activity of animals, hence leading to improved animal health. Natural antioxidants supplied through forage grasses and legumes can also prolong the shelf life of meat and milk and protect meat from losing its desirable red color $[1,2]$. The freshness, fat content, flavor and color of meat are key factors used to judge the quality of meat by consumers, and diet has a potent influence on these factors [3-5]. The rate of loss of the red color is related to the degree of unsaturation of lipids and the presence of antioxidants supplied through the diet [6]. Natural antioxidants from plants also protect unsaturated fatty acids such as n-3 fatty acids from oxidation [7]. Conjugated linoleic acid (CLA) was reportedly much higher for pasture-fed cattle than for concentrate-fed cattle [8], and pasture contains a high amount of the precursor of CLA, i.e., polyunsaturated C18:2, linoleic acid [9] which could be protected from oxidation by antioxidants from feed. It is generally considered that fresh pastures are the principal supplier of antioxidants to animals [2]. Ensuring the supply of antioxidants through pastures is essential to produce good quality products from animals. As a result, natural herbs and pastures having high antioxidative activities have attracted considerable interest from scientists as well as feed manufacturers [10]. However, antioxidant properties vary from species to species and within species due to 
environmental effects. For example, Collomb et al. [11] have reported that the composition related to antioxidative activities of milk and cheese differ depending on different altitudinal locations. The content of acteoside, an antioxidant, in forage herb plantain varies due to air temperature, light intensity, fertilizer application and harvesting season $[12,13]$. Plantain has a higher amount of superoxide anion radical scavenging activity (SOSA) than the principal temperate pastures used in northern Japan [14]. Despite the importance of natural herbs and pastures as a source of antioxidants, little attention has been paid to the determination of antioxidative properties of herbs and pastures. Few experiments have been carried out; including those of Lee et al. [15] on the antioxidative activities of alfalfa and timothy varieties using the DPPH method, and by Tamura and Masumizu [16] and Al-Mamun et al. [14] on SOSA measured using an ESR-spin trapping method for $\mathrm{s}$ limited number of pasture and herb species. Therefore, the present study was undertaken to find out the variation in the SOSA among a wide range of herbs and pastures, including grasses and legumes, collected from different altitudes in northern Japan.

\section{Materials and Methods}

\section{Plant materials and preparation}

Samples of herbs and pastures were collected at 3 $\mathrm{cm}$ above ground level from two swards differing in altitude, namely the Yamagami sward (lowlands, $\mathrm{N}$ $36^{\circ} 5^{\prime} \mathrm{E} 141^{\circ} 00^{\prime}$ and $177 \mathrm{~m}$ above sea level) and the Hayasaka sward (highlands, N 39 $81^{\prime}$ E141 ${ }^{\circ} 47^{\prime}$ and $920 \mathrm{~m}$ above sea level), which are usually used for harvesting hay and grazing by Japanese shorthorn cattle during the summer. From the lowlands, we collected one herb, plantain (PL, Plantago lanceolata L.), and nine dominant pasture species; perennial ryegrass (PR, Lolium perenne L.), orchardgrass (OR, Dactylis glomerata L.), timothy (TI, Phleum pretense L.), white clover (WC, Trifolium repens L.), quackgrass (QG, Agrophyron repens L.), reed canarygrass (RC, Phalaris arundinacea L.), Kentucky bluegrass (KB, Poa pratensis L.), Japanese lawngrass (JL, Zoyocia japonica L.) and alfalfa (AL, Medicago sativa $\mathrm{L}$.) in the vegetative stage on 5 May, 2006. From the highlands we also collected one herb, dandelion (DD, Taraxacum officinale Weber) and five dominant pasture species; PR, OR, TI, WC and QG, at the vegetative stage on 26 May, 2006. The samples from the highlands were collected 3 weeks later than those of the lowlands in order to compare the same growth stage because the daily mean air temperature was higher at the latter (Fig. 1).

The samples from the two swards were then freeze-dried in a FRD-50M freeze-drier (Iwaki Glass Co., Ltd., Japan) and ground to a fine powder using a vibrating sample mill (Heko Co. Ltd., Japan). Each of the $1 \mathrm{mg}$ of ground samples was extracted either into $10 \mathrm{~mL}$ of water ( $\mathrm{pH}$ adjusted to 7.4 with phosphate buffer) or into $10 \mathrm{~mL}$ of pure $\mathrm{MeOH}$, with linear shaking for 1 hour at a speed of 130 revolutions hour-1 at room temperature. Finally, the samples were centrifuged at $3500 \mathrm{rpm}$ for $10 \mathrm{~min}$ and the eluents used for the determination of SOSA by an ESR-spin trapping method. The experiment was conducted with three replicates.

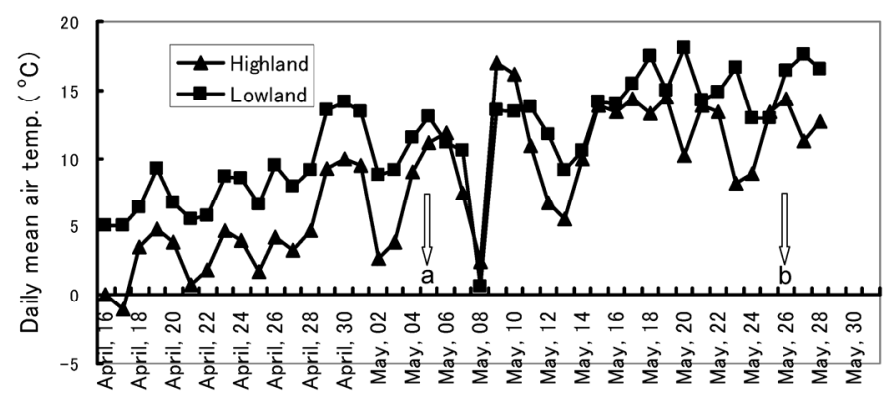

Figure 1 . The daily mean air temperature $\left({ }^{\circ} \mathrm{C}\right)$ during sampling of the experimental areas. a, b; date of sampling at lowlands and highlands, respectively.

\section{Chemicals used}

Superoxide dismutase (SOD) from bovine erythrocytes (Nacalai Tesque Inc., Kyoto, Japan); trapping agent 5,5-dimethyl-1-pyroline-N-oxide (DMPO) (Labotec Co. Ltd., Tokyo, Japan); hypoxanthine (HPX) (Sigma Chemical Co., Tokyo, Japan); xanthine oxidase (XOD) for active oxygen generation (Roche Chemical Co., Tokyo, Japan); phosphate buffered solution $\mathrm{pH} 7.4$ (1/15 mol $\mathrm{L}^{-1}$ )(Kanto Chemical, Tokyo, Japan); methanol (Wako Chemical, Osaka, Japan); catechin (Extrasynthes Inc. Genay, France); and Folin-Denis reagent (Sigma Chemical Co. MO, USA) were used.

\section{Determination of SOSA}

The SOSA was determined through a spin trapping method using an ESR spectrometer (JES-FA200, JEOL Ltd., Tokyo, Japan). Manganese oxide was used as an internal standard, which provided a constant signal intensity to which all peaks were compared. ESR spectrometer measurement conditions used to estimate $\mathrm{O}_{2}{ }^{-}{ }^{-}$were as follows: magnetic field: $335 \pm 5 \mathrm{mT}$; power: $4 \mathrm{~mW}, 9.42 \mathrm{GHz}$; sweep time: $2 \mathrm{~min}$; modulation frequency: $100 \mathrm{kHz}$, $0.08 \mathrm{mT}$; amplitude: $2.5 \times 100$; time constant: $0.1 \mathrm{sec}$.

An HPX-XOD reaction system was used to determine SOSA. The chemicals were mixed in the following order: $15 \mu \mathrm{L}$ of $9.2 \mathrm{~mol} \mathrm{~L}^{-1} \mathrm{DMPO}, 50 \mu \mathrm{L}$ of 2 mmol L-1 HPX, $35 \mu \mathrm{L}$ of water ( $\mathrm{pH} 7.4$, adjusted using $\mathrm{PB}), 50 \mu \mathrm{L}$ of samples, and finally, $50 \mu \mathrm{L}$ of $0.4 \mathrm{U} \mathrm{mL}^{-1}$ $X O D$ from cow's milk. The mixture was transferred to an ESR spectrometry flat cell and the DMPO-O ${ }_{2}{ }^{\cdot-}$ spin adduct was quantified for $1 \mathrm{~min}$ after the addition of XOD. Standard curves were made for both water and $\mathrm{MeOH}$ extracted samples and the SOSA was expressed as SOD equivalent units per milligram dry matter (DM) [17].

\section{Determination of crude phenolics}

Total polyphenol measurement of freeze-dried herb and pastures from the highlands was performed according to the Folin-Denis colorimetric method [18]. 
Each of the 0.03-0.04 $\mathrm{g}$ of freeze-dried samples was first mixed with 5 volumes of water or $\mathrm{MeOH}$, and kept for 2 hours at room temperature before centrifugation at 10,000 rpm for $10 \mathrm{~min}$. Then, $0.1 \mathrm{~mL}$ of the supernatant was mixed with $0.1 \mathrm{~mL}$ of Folin-Ciocalteau's reagent. After $10 \mathrm{~min}, 0.1 \mathrm{~mL}$ of $10 \%$ saturated sodium bicarbonate was added and mixed well. After 1 hour the absorbance of the mixed samples at $655 \mathrm{~nm}$ was measured by a spectrophotometer. Catechin was used as the standard to which the samples were compared.

\section{Determination of vitamin $\mathbf{C}$}

Freeze-dried samples from the highlands were used to determine vitamin $C$ content using high performance liquid chromatography (HPLC) (LC 10AS, Shimadzu Co., Ltd., Kyoto, Japan). Quantitative analyses were performed at $35^{\circ} \mathrm{C}$ using a $4.6 \mathrm{~mm} \times 10$ $\mathrm{cm}$ column (Senshupak silica-1100-N). The mobile phase was an acetyl ether, n-hexane, acetic acid and water (60:40:5:0.05) solution. The flow rate was $1.5 \mathrm{~mL}$ $\min ^{-1}$. Photodiode array detection was performed at $495 \mathrm{~nm}$. First, $0.5 \mathrm{~g}$ of freeze-dried sample was extracted into $50 \mathrm{~mL}$ of $5 \%$ metalinic acid, homogenized and then centrifuged at $3000 \mathrm{rpm}$ for 10 $\min$. Then $1 \mathrm{~mL}$ of the eluent was mixed with $1 \mathrm{~mL}$ of $5 \%$ metalinic acid, $100 \mu \mathrm{L}$ of $0.2 \% \quad 2,6$ dichlorophenol-indophenol sodium salt dehydrate and $2 \mathrm{~mL}$ of $2 \%$ thiourea- $5 \%$ metalinic acid solution were added into the test tube. After that $0.5 \mathrm{~mL}$ of $2 \%$ of 2,4-dinitrophenol hydrazine- $4.5 \mathrm{~mol} \mathrm{~L}^{-1} \mathrm{H}_{2} \mathrm{SO}_{4}$ was added and kept at $38-42{ }^{\circ} \mathrm{C}$ for 16 hours. Finally $3 \mathrm{~mL}$ of acetyl ether was added and the mixture was shaken for 1 hour, and then used for determination of ascorbic acid by HPLC.

\section{Statistical analysis}

All data were expressed as mean values with standard error of the mean (SEM). Statistical analysis was performed using the General Linear Model procedure of SAS with Tukey's Studentized range (HSD) test of the SAS system [19]. In the case of individual species we used Student's $t$-test to compare the water and $\mathrm{MeOH}$ extracted SOSA and polyphenol content and the SOSA values of highlands and lowlands.

\section{Results and Discussion}

\section{Differences in SOSA among herbs and pastures of lowlands}

The SOSA of herb and pastures varied largely among species both in the water and $\mathrm{MeOH}$ extracts (Fig. 2). For the water extracted SOSA, WC showed the highest and PL was the second highest of the pastures while PR, TI, KB, JL and AL grouped significantly to the lowest. OR, RC and QG were in between PL and the lowest group.

On the other hand, for MeOH extracted SOSA, PL showed an extremely high SOSA that was significantly higher than that of pastures. Among the grass species, TI and QG were significantly higher than other grasses and PR, RC, KB and JL grouped significantly to the lowest SOSA while OR was in between. In the case of the leguminous species, WC showed very low SOSA, and no detectable SOSA was found in AL.
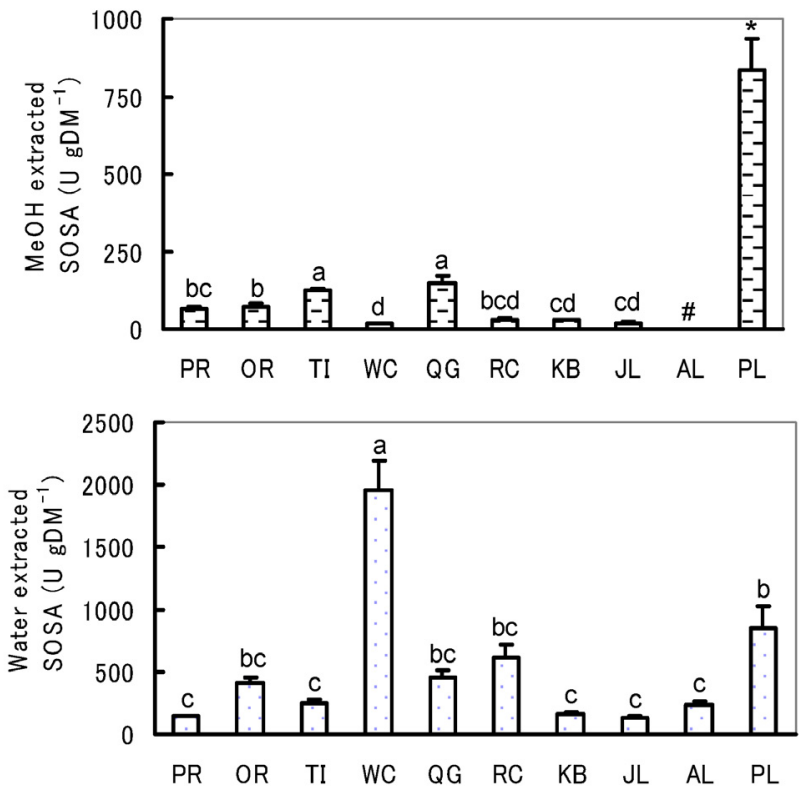

Figure 2. Water and $\mathrm{MeOH}$ extracted SOSA of herb and pastures of lowlands. Values with different superscripts differed significantly $(P<0.05)$. \# Not detected. Note: Regarding Tukey's Studentized range (HSD) test for the $\mathrm{MeOH}$ extracted SOSA, we did the analysis twice, first for all species and secondly only for pastures, as PL was much higher than any of the pastures.

The most interesting observation was species variations between extraction methods. For instance, SOSA of WC was the highest in water extracts but the lowest in $\mathrm{MeOH}$ extracts. On the other hand, in PL, the $\mathrm{MeOH}$ extracted SOSA was extremely high, but that of water was relatively low, about half of the SOSA of WC. TI was the lowest for water extracted SOSA, but was highest for the $\mathrm{MeOH}$ extracted SOSA among the pastures. In PR, KB and JL, both the water and $\mathrm{MeOH}$ extracted SOSA were very low.

The present results indicate that the amount and kind of antioxidants accumulating differ largely between herbs and pastures and among pastures. Therefore, selection of pastures having higher antioxidative activity would be very important to improve animal health and the antioxidative status of meat and milk, and to prolong their shelf life. The effect of the water and $\mathrm{MeOH}$ extracted SOSA on animal health and on meat and milk quality is not clarified yet, but it could be considered that $\mathrm{MeOH}$ extracted SOSA is more important than water extracted SOSA, since $\mathrm{MeOH}$ extracted SOSA represents lipid soluble antioxidants. Bioactive compounds in each species having antioxidative activity are still not known in detail except for acteoside, a phenylethanoid compound that has high antioxidative activity [20]. The higher $\mathrm{MeOH}$ extracted SOSA of PL might be due to the presence of acteoside, 
and the higher water extracted SOSA of WC might be due to higher vitamin $C$ content than in the other pastures as reported by Tamura and Masumizu [16], and higher water soluble total polyphenol content. It is necessary to clarify the type of antioxidants and their mode of action in each species.

\section{Differences of SOSA among herbs and pastures of highlands}

The SOSA of herb and pastures also varied largely among species both for water and $\mathrm{MeOH}$ extracts (Fig. 3). For water extracted SOSA, WC showed the highest SOSA, and QG and DD also had significantly higher SOSA than PR, OR and TI. On the other hand, for the $\mathrm{MeOH}$ extracted SOSA, DD was significantly the highest while that of WC was the lowest. The PR, OR, TI and QG were in between DD and WC and no significant difference was found among them. The most interesting observations here were almost the same as found for the lowlands. For instance, WC showed the highest water extracted SOSA while that of $\mathrm{MeOH}$ extracts was the lowest, and among the pastures, TI had the highest $\mathrm{MeOH}$ extracted SOSA while that of water extracts was very low. Furthermore, we found that DD was very high both for the water and $\mathrm{MeOH}$ extracted SOSA.
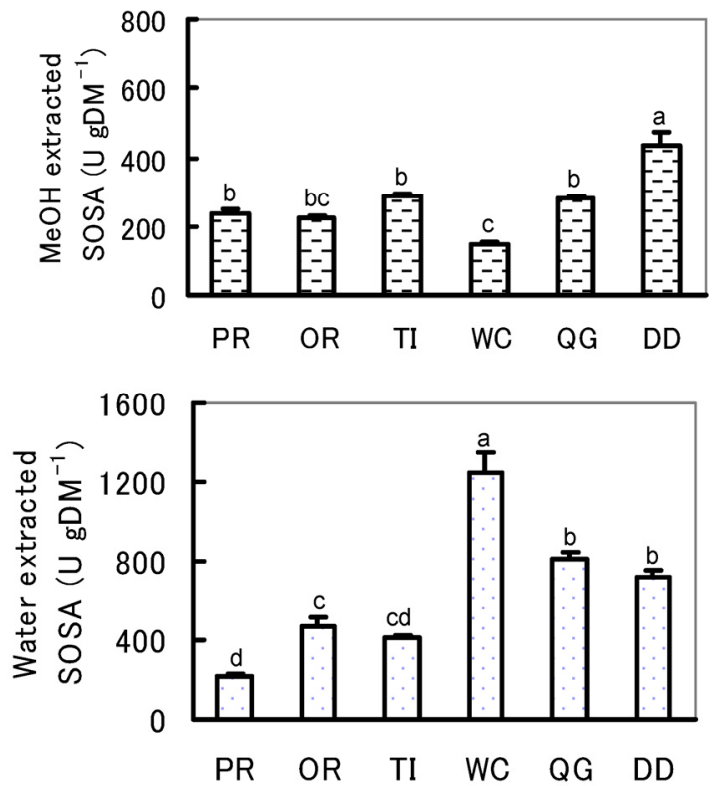

Figure 3. Water and $\mathrm{MeOH}$ extracted SOSA of herb and pastures at highlands. Values with different superscripts differed significantly $(P<0.05)$.

The present results obtained among species were basically the same between locations of different altitude. We conclude that the differences in both the water and $\mathrm{MeOH}$ extracted SOSA found in the present experiment might be attributable to the genetic characteristics of each species.

\section{Comparison of SOSA between lowlands and highlands}

In the present experiment, only five species, PR,
OR, TI, WC and QG, were compared, as they were available in both lowlands and highlands. The water extracted SOSA of WC was higher in lowlands than in highlands, whereas other pastures remained comparable between locations of different altitude (Fig. 4). The reason why the water extracted SOSA of WC in lowlands was so much higher than that of highlands is unknown. But it could be considered that the residual effects of a cold winter in the highlands negatively affected the spring growth of WC, which is less winter hardy than the graminaceae species.
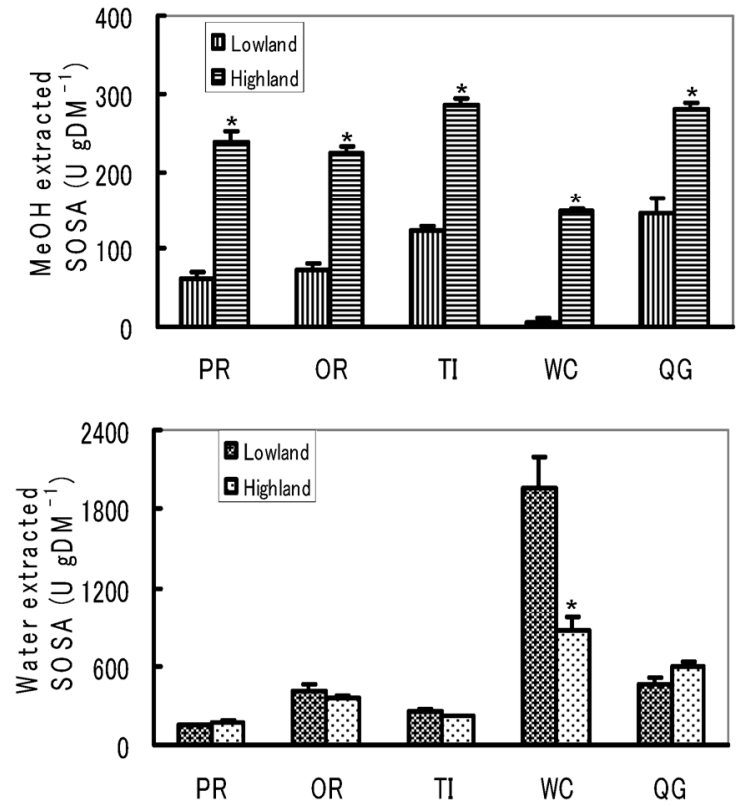

Figure 4. Comparison of the water and $\mathrm{MeOH}$ extracted SOSA contents of the common species between lowlands and highlands. ${ }^{*} \mathrm{P}<0.05$.

On the other hand, the MeOH extracted SOSA were very significantly higher in the highlands than the lowlands in all of the common species. The higher the altitude, the higher the amount of ultraviolet (UV) rays in sunlight that reaches the ground, as reported by Caldwell and Robberecht [21]. There have been many reports on the effects of UV irradiation on the accumulation of methanol soluble flavonoids and phenolic compounds in plants. For instance, Poulet et al. [22] showed that natural pasture from a mountain region had a greater amount of phenolics, which are antioxidants known to influence taste and preservation of animal products, than hay and silages made from principal forage grasses and crops such as perennial ryegrass, orchardgrass and maize. Highly positive correlations between the amount of UV radiation, both from sunlight and due to artificial radiation, and the accumulation of flavonoids and phenolic compounds were reported in some plant species [23-25]. Ingestion of plants at high altitudes that get more UV flux provides significant protection against ionizing radiation in experimental animals [26]. Therefore, we considered that the higher $\mathrm{MeOH}$ extracted SOSA of plants from the highlands could be 
attributable to higher amounts of flavonoids and phenolic compounds due to higher UV radiation.

\section{Polyphenol and vitamin $C$ contents and their relationship to SOSA}

All of the water and $\mathrm{MeOH}$ extracted polyphenol and vitamin $C$ contents differed significantly among herbs and pastures (Fig. 5, 6). For example, the water extracted polyphenol and vitamin $C$ contents were significantly highest in WC and lowest in DD. Among other species, vitamin $\mathrm{C}$ content was significantly higher in PR, TI and QG than in OR, but no significant difference was observed in water extracted polyphenol. $\mathrm{MeOH}$ extracted polyphenol was significantly highest in TI and higher in QG and DD than other pastures, while OR was the lowest. The highest water extracted SOSA being found in WC might be due to its having the highest contents of both polyphenol and vitamin C [16]. On the other hand, the highest $\mathrm{MeOH}$ extracted SOSA in TI might be due to its having the highest $\mathrm{MeOH}$ extracted polyphenol. The same prediction is also applicable for DD and QG. Though the SOSA obtained in the present study may be related to the concentrations of polyphenol and vitamin $C$, the relationships are not that clear and the contribution coefficients of the polyphenol and vitamin C to SOSA were relatively low (Fig. 7). Other antioxidants presumably also affect the level of SOSA. DD was considered the most typical example, because although its water extracted polyphenol and vitamin C contents were the lowest, the water extracted SOSA was relatively high, indicating the presence of unknown water soluble antioxidants. Therefore, the determination of only polyphenol and and vitamin C is not enough to represent the antioxidative properties of an herb or pasture. The determination of total antioxidative properties by ESR-spin trapping or other established methods is essential.
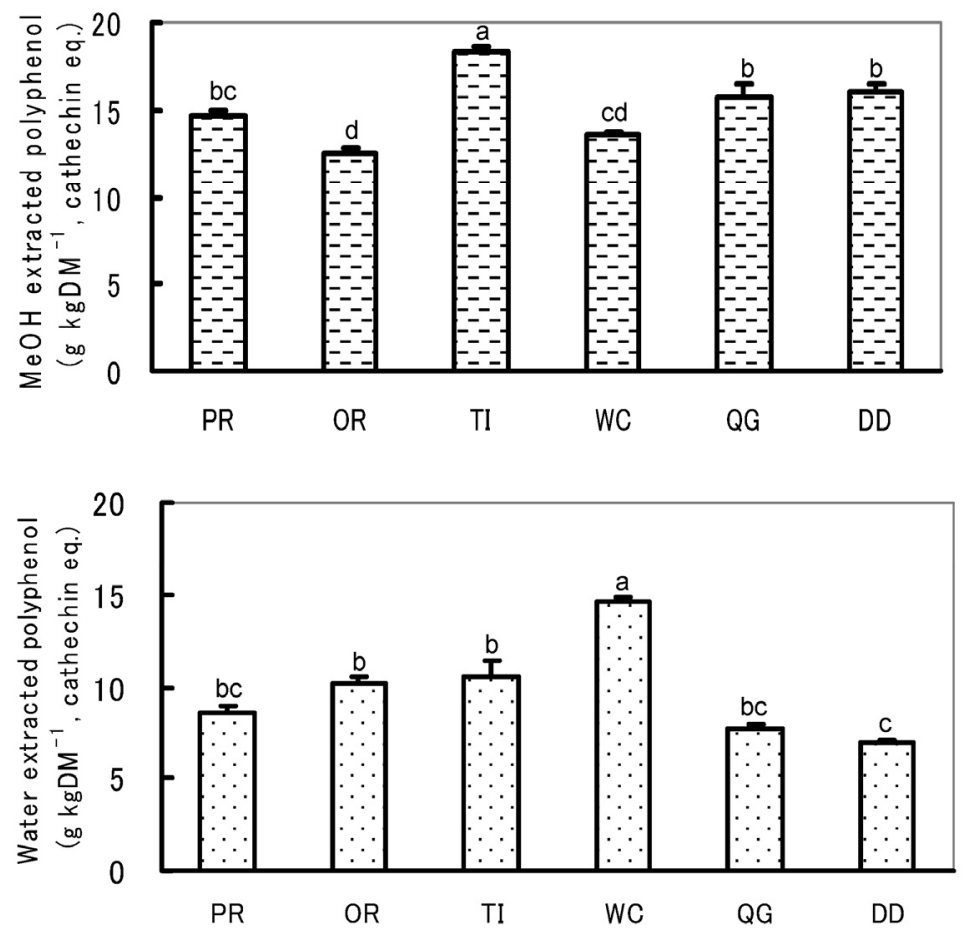

Figure 5. Water and $\mathrm{MeOH}$ extracted polyphenols of herbs and pastures of highlands. Values with different superscripts differed significantly $(P<0.05)$.

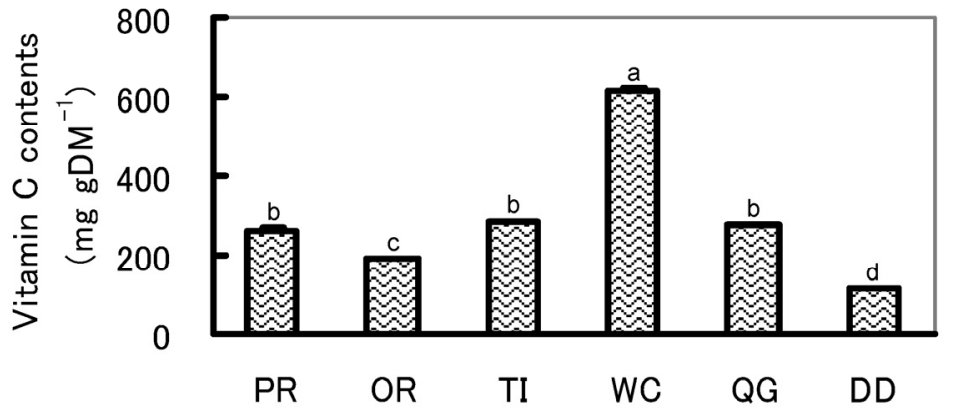

Figure 6. Vitamin C content of herbs and pastures of highlands. Values with different superscripts differed significantly $(P<0.05)$. 

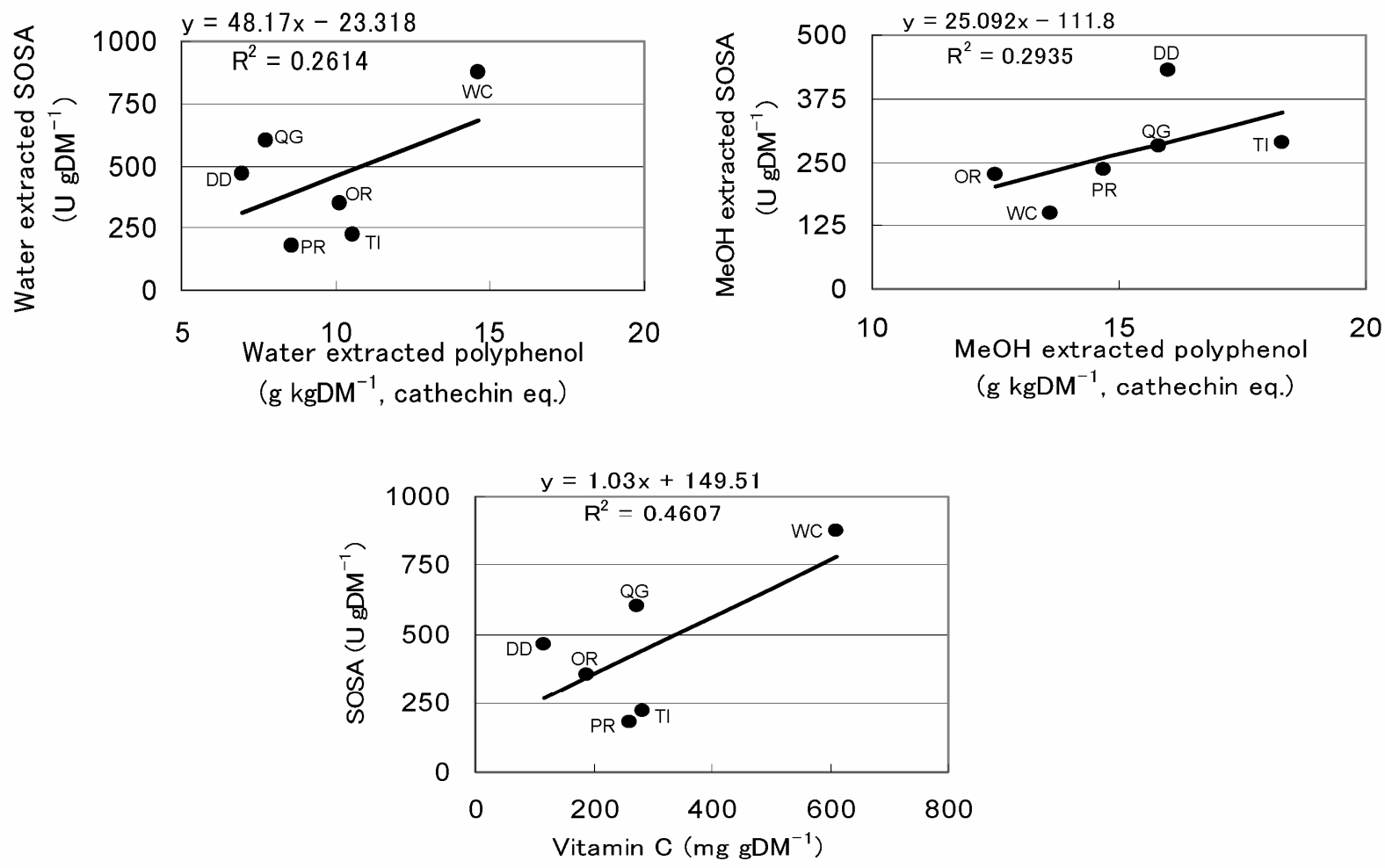

Figure 7. Relationship of SOSA to polyphenol and vitamin C content.

\section{Conclusions}

From the present experiments it could be concluded that the antioxidant properties represented by both water and $\mathrm{MeOH}$-extractable SOSA vary largely among species of the herbs and pastures available in northern Japan, and also vary depending on the altitudinal location. As a pioneer experiment, the results are promising and some of the species, especially PL, WC, DD, QG and TI, could be used as natural sources of antioxidants against superoxide radicals to protect animals from adverse effects of $\mathrm{O}_{2}{ }^{\cdot-}$. However, based on the present experiments, further research should be performed to clarify specific antioxidants and their mode of actions in order to proper selection and combination of the herbs and pastures to improve the animal health ensuring the quality of animal products.

\section{Acknowledgements}

The authors thank to Professor emeritus Sansei Nishibe, Health Science University of Hokkaido for helpful suggestions, and Dr. Kanno and Mr. Deguchi, National Agricultural Research Center for Tohoku Region for providing air temperature data.

\section{Conflict of interest}

The authors have declared that no conflict of interest exists.

\section{References}

1. Muramoto T, Higashiyama $M$, Kondo T. Effects of pasture finishing on beef quality of Japanese Shorthorn steers.
Asian-Aust J Anim Sci. 2004;18:420-426

2. Scollan ND, Dewhurst RJ, Mononey AP, Murphy JJ. Improving the quality of products from grassland, Grassland: A Global Resource. Proc XX Int Grassl Cong. 2005;:41-56

3. Murphy TA, Loerch SC, McClure KE, Solomon MB. Effects of grain or pasture finishing systems on carcass composition and tissue accretion rates of lambs. J Anim Sci.1994;72:3138-3144

4. Rousset-Akrim S, Young OA, Berdagué JL. Diet and growth effects in panel assessment of sheepmeat odour and flavour. Meat Sci. 1997;45:169-181

5. Prache S, Theriez M. Traceability of lamb production systems: carotenoids in plasma and adipose tissue. Anim Sci. 1999;69:29-36

6. O'Sullivan A, Galvin K, Moloney AP, Troy DJ, O'Sullivan K, Kerry JP. Effect of pre-slaughter ration of forages and or concentrates on the composition and quality of retail packaged beef. Meat Sci. 2003;63:279-286

7. Melton SL. Effects of feeds on flavor of red meat: a review. J Anim Sci. 1990;68:4421-4435

8. Realini CE, Duckett SK, Brito GW, Dalla RM, De Mattos D. Effect of pasture vs. concentrate feeding with or without antioxidants on carcass characteristics, fatty acid composition, and quality of Uruguayan beef. Meat Sci. 2004;66:567-577

9. Bauman DE, Corl BA, Baumgard LH, Griinari JM. Conjugated linoleic acid (CLA) and the dairy cow. In: Garnsworthy PC, Wiseman J, ed. Recent Advances in Animal Nutrition - 2001. UK: Nottingham University Press; 2001: 221-250

10. Gill C. Herbs and plant extracts as growth enhancers. Feed Management. 1999;50:29-32

11. Collomb M, Butikofer U, Sieber R, Jeangros B, Bosset JO. Correlation between fatty acids in cows' milk fat produced in the lowlands, mountains and highlands of Switzerland and botanical composition of the fodder. Int Dairy J. 2002;12:661-666

12. Tamura Y. Environmental changes and genetic variation of accumulation of bioactive compounds in plantain (Plantago 
lanceolata L.). Bull Natl Agric Res Cent Tohoku Reg. 2002;100:75-92

13. Tamura $Y$, Nishibe $S$. Changes in the concentrations of bioactive compounds in plantain leaves. J Agric Food Chem. 2002;50:2514-2518

14. Al-Mamun M, Tamura $Y$, Nakai $Y$, Masumizu T, Sano H. Evaluation of free radical scavenging activities of plantain (Plantago lanceolata L.) herb and other pastures by ESR. Proc 12th AAAP Anim Sci Cong. 2006;3:1084-1086

15. Lee JK, Park HS, Kim JG, Paek BH, Fike JH. Antioxidative activities of alfalfa and timothy varieties. Proc XX Int Grassl Cong. 2005; :194

16. Tamura Y, Masumizu T. Evaluation of superoxide anion radical scavenging activities of plantain and pastures by electron spin resonance (ESR). Proc XX Int Grassl Cong. 2005; :275

17. Noda Y, Anzai K, Mori A, Kohno M, Shinmei M, Packer L. Hydroxyl and superoxide anion radical scavenging activities of natural source antioxidants using the computerized JES-FR30 ESR spectrometer system. Biochem Mol Biol Int. 1997;42:35-44

18. Folin O, Denis WA. Colorimetric method for the determination of phenols (and phenol derivatives) in urine. J Biol Chem. 1915;22:305-308

19. SAS (Statistical Analysis System). SAS User's Guide (4th ed.), Version 6. Cary, NC: SAS Institute. 1994.

20. Nishibe S, Murai M. Bioactive components of plantago herb. Food Food Ingred J Jpn. 1995;166:43-49

21. Caldwell MM, Robbereht R. A steep latitudinal gradient of solar ultraviolet-B radiation in the arctic alpine life zone. Ecology. 1980;61:600-611

22. Poulet JL, Fraisse D, Viala D, Carnat A, Pradel P, Martin B, Lamaison JL, Besle JM. Flavonoids in forages: composition and possible effects on milk quality. Proc 19th General Meeting Eur Grassl Federation, Grassl Sci Eur. 2002;7:590-591

23. Begges CJ, Schneider-Zeibert U, Wellmann E. UV-B radiation and adaptive mechanisms in plants. In: Worrest RC, Caldwell MM, ed. Stratospheric Ozone Reduction, Solar Ultraviolet Radiation and Plant Life, Heidelberg: Springer-Verlag Berlin; 1986: 235-250.

24. Yoshida M. Physiological changes of plants to the intensities of ultraviolet radiation in mountainous area (M.S. thesis). Japan: Shinshu university. 1991

25. Liang B, Huang X, Zhang G, Zhang F, Zhou Q. Effect of lanthanum on plants under supplementary ultraviolet-B radiation: effect of lanthanum on flavonoid contents in soybean seedlings exposed to supplementary ultraviolet-B radiation. J Rare Earth. 2006;24:613-616

26. Arora R, Chawla R, Sagar R, Prasad J, Singh S, Kumar R, Sharma A, Singh S, Sharma RK. Evaluation of radioprotective activities of Rhodiola imbricate Edgew-a high altitude plant. Mol Cell Biochem. 2005;273:209-223 